\title{
Acid Phosphatases of Sporothrix schenckii
}

\author{
By WILFRED N. ARNOLD,* LARRY C. MANN, KAZUHIKO H. SAKAI, \\ ROBERT G. GARRISON AND PAUL D. COLEMAN \\ Department of Biochemistry, University of Kansas Medical Center, Kansas City, \\ Kansas 66103, USA
}

(Received 12 March 1986; revised 17 June 1986)

\begin{abstract}
Sporothrix schenckii cells were grown on a medium containing yeast extract, neopeptone and glucose at $20^{\circ} \mathrm{C}$ to obtain a mixture of mycelia and conidia, and at $35^{\circ} \mathrm{C}$ to obtain yeast-like cells. The organism was maintained in the mycelial form, and its transformation to yeast at the higher temperature proceeded via conidia and 'intermediate cells' that then gave rise to yeast by a blastic mechanism. Cell-free extracts were analysed by PAGE at $\mathrm{pH} 8.0$ and acid phosphatases (EC 3.1.3.2) were revealed by a sensitive detection reagent at $\mathrm{pH} 5 \cdot 0$. Mycelial, conidial and yeast extracts all had some acid phosphatase activity (M-I, C-I and Y-I) at the origin, although the proportion was highest for the yeast extracts. All of the bands that penetrated the gels had different electrophoretic mobilities. Mycelial and conidial extracts each had one other isoenzyme (M-II and C-II), while the yeast extracts had a total of five electrophoretically distinct acid phosphatases. Isoenzyme Y-II was further resolved into five closely related bands (Y-II $a$ to $\mathrm{Y}$-II $e$ ), the relative intensities of which varied with the phosphate nutrition of the yeast cells and the history of the extracts. The acid phosphatase isoenzymes were inhibited to various extents by sodium fluoride, $\mathrm{L}(+)$-tartrate and phosphate, and showed interactions with citrate as opposed to acetate as the background buffer at $\mathrm{pH} 5 \cdot 0$.
\end{abstract}

\section{INTRODUCTION}

Sporothrix schenckii, the causative agent of sporotrichosis in man and other animals, is a dimorphic fungus with a world-wide distribution in soil and on plants. The frequency of infections in the Americas, and occasional epidemics elsewhere, indicate its clinical importance. The saprophytic form of $S$. schenckii is mycelial, while the disease is caused by the proliferation of yeast-like cells within the host tissue. Several studies on $S$. schenckii cell types have examined differences in ultrastructure and immunochemistry of surface antigens (see, e.g., Travassos \& Lloyd, 1980). However, apart from a survey of enzymic activities of extracts of yeast-phase cells (Walbaum et al., 1978), little attention has been paid to the enzymology of $S$. schenckii. Furthermore, in this, and all other dimorphic fungi, putative differences in the key enzymes of yeast and mycelial cells have not been shown.

Garrison \& Arnold (1983) used cytochemistry at the electron microscope level to demonstrate a multiplicity of acid phosphatase (EC 3.1.3.2) activity sites in yeast- and mycelial-phase cells of S. schenckii. We now report on further studies with cells and extracts, and demonstrate by gel electrophoresis some striking differences in the acid phosphatase isoenzymes among different cell types.

\section{METHODS}

Organism and media. S. schenckii (Institut Pasteur Strain \# 29) was maintained in mycelial-phase by weekly transfer on agar slants (for composition see Darling et al., 1969). Standard YNG for liquid cultures contained yeast extract (Difco) $(0.3 \%, w / v)$, neopeptone (Difco) $(0.5 \%, w / v)$ and glucose $(1 \%, w / v)$. A modified version of this medium ('S' medium) contained magnesia-treated yeast extract in order to lower the phosphate concentration from $2 \mathrm{mM}$ (as in YNG) to $<0.02 \mathrm{mM}$ (Arnold \& Garrison, 1979). Other media that were used included Brain

Abbreviations: YNG, yeast extract/neopeptone/glucose medium; BHI, Brain Heart Infusion medium. 
Heart Infusion medium (BHI; Difco) and YNG fortified with phosphate to a total concentration of $18 \mathrm{~mm}$ (to match that in $\mathrm{BHI}$ ).

Inocula. These were mostly obtained, as a mixture of mycelia and conidia, from 3-5 d gently stirred YNG liquid cultures at $23^{\circ} \mathrm{C}$, and were used at a rate of $1 \mathrm{mg}$ dry wt cells per $40 \mathrm{ml}$ fresh medium. For certain experiments, mycelia and conidia were separated by filtration (see below), under aseptic conditions; they were used at the same rate as the mixture. In regulating inoculum size, and in monitoring growth, the turbidimetric method of Bestic \& Arnold (1976) was used.

Mycelial phase. Optimum production of mycelia (and conidia) was achieved by growth on YNG at $20^{\circ} \mathrm{C}$, with gentle rotary shaking ( 100 r.p.m.). After $3 \mathrm{~d}$ the cell suspension was poured into a cone of Miracloth (CalbiochemBehring); the bulk of the conidia passed through the filter and the retained mycelial strands were further purified by irrigation with $0.25 \mathrm{M}$-sodium acetate buffer ( $\mathrm{pH} 6.5$ ). The conidia and mycelia were washed separately by successive steps of resuspension and centrifugation and were finally suspended to $20 \%$ (wet wt/vol.) in the same buffer.

Yeast phase. Vigorous shaking (175 r.p.m.) in YNG at $35^{\circ} \mathrm{C}$ resulted in a $3 \mathrm{~d}$ culture almost exclusively composed of yeast-like cells. Cells were harvested by centrifugation, washed in $0.25 \mathrm{M}$-sodium acetate buffer (pH 6.5) and resuspended in the same buffer to $20 \%$ (wet wt/vol.).

Light microscopy. Samples were mounted on small agar slabs, placed under cover slips (Robinow, 1975), and then photographed under dark-field, phase-contrast microscopy.

Cell-free extracts. Usually cells were broken by extrusion through a French pressure cell at $138 \mathrm{MPa}$ and $4{ }^{\circ} \mathrm{C}$. For comparative purposes some disruptions were made by bombardment with glass beads (Bead-Beater; Biospec Products, Bartesville, Oklahoma, USA) in an ice-water bath or by extrusion of a frozen suspension (X-press; AB Biox, Stockholm, Sweden) at $193 \mathrm{MPa}$ and $-25^{\circ} \mathrm{C}$. Preparations were cleared by centrifugation at $20200 \mathrm{~g}$ for $20 \mathrm{~min}$ at $4^{\circ} \mathrm{C}$, and the supernatant fractions were passed through membrane filters $(0.22 \mu \mathrm{m}$ pore size; Millipore).

Gel electrophoresis. Polyacrylamide $(7 \cdot 7 \%$ total acrylamide, $2.6 \%$ bis-acrylamide crosslinker) gel electrophoresis was done in a continuous buffer system (Hjerten et al., 1965) using $80 \mathrm{mM}$-glycine $/ 5 \mathrm{mM}$-Tris (pH 8.0 ) at $4^{\circ} \mathrm{C}$. The gels were cast as cylinders $(0.5 \mathrm{~cm}$ diam. $\times 9 \mathrm{~cm})$ using ammonium persulphate (final concentration $0.6 \mathrm{mg} \mathrm{m}^{-1}$ ), tetramethylethylenediamine $\left(0.29 \mu \mathrm{ml}^{-1}\right)$ and potassium ferricyanide $\left(31 \mu \mathrm{g} \mathrm{ml}^{-1}\right)$ as a catalyst to elicit gelation in $40 \mathrm{~min}$. Unreacted monomers and catalyst were removed by subjecting the gels to $200 \mathrm{~V}$ at $4{ }^{\circ} \mathrm{C}$ for at least $2 \mathrm{~h}$ so that a tracking dye completely traversed the gel cylinders. Upper and lower chambers were then refilled with fresh buffer and the samples were applied.

Sample preparation. Immediately before electrophoresis the sample was equilibrated with $20 \mathrm{mM}$-glycine/Tris (pH 7.5) by gel permeation chromatography through Sephadex G-25 (Pharmacia). A sample (5 ml) was applied to a column ( $42 \mathrm{ml}$ ) previously equilibrated with the $\mathrm{pH} 7.5$ buffer and eluted at $1 \mathrm{ml} \mathrm{min}{ }^{-1}$. All the acid phosphatase activity emerged in the void volume. Fractions $(2 \mathrm{ml})$ were collected and assayed: $1 \mathrm{ml}$ of the peak activity fraction

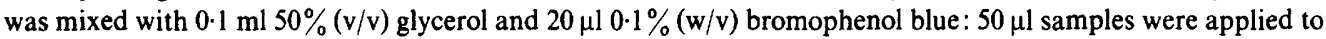
each gel. Sample zone sharpening was due to an initial conductivity jump but a low current was maintained during migration of the sample into the gel in order to minimize the risk of thermal convection and denaturation (Hjerten et al., 1965). The potential was then increased to $200 \mathrm{~V}$; this gave a current of $0.3 \mathrm{~mA}$ per gel, which was constant for the duration of the run $\left(2 \mathrm{~h}\right.$ at $\left.4^{\circ} \mathrm{C}\right)$.

Acid phosphatase activity stain. After electrophoresis the gels were removed from their glass tubes, covered with $0.2 \mathrm{M}$-sodium acetate buffer ( $\mathrm{pH} 5.0$ ), and gently rocked in a reciprocal shaker at $4{ }^{\circ} \mathrm{C}$ for $20 \mathrm{~min}$. Each gel was then individually incubated with $4 \mathrm{ml}$ of a reagent, slightly modified from that described by Davis \& Ornstein (1959), which contained $\alpha$-naphthyl phosphate $\left(1 \mathrm{mg} \mathrm{ml}^{-1}\right)$ and freshly diazotized pararosaniline $\left(1 \mathrm{mg} \mathrm{ml}^{-1}\right)$ in $0.2 \mathrm{M}$-sodium acetate buffer $(\mathrm{pH} 5.0)$. When potential inhibitors were investigated the detection mixture was fortified appropriately as were the buffers for preincubation $\mathrm{pH}$ adjustment and postincubation washing. Incubations were done at $23^{\circ} \mathrm{C}$, in subdued light, by tumbling the gels within slightly larger glass tubes, for, typically, $2 \mathrm{~h}$. After this time the gels were washed in buffer at $4^{\circ} \mathrm{C}$ and then exhaustively washed in $7 \%(\mathrm{v} / \mathrm{v})$ acetic acid. The enzymograms were stored in this solution in screw-capped tubes at $4^{\circ} \mathrm{C}$.

Enzyme unit. One international unit (IU) of acid phosphatase is the amount that catalyses the hydrolysis of $1 \mu \mathrm{mol} p$-nitrophenyl phosphate $\min ^{-1}$ at $30^{\circ} \mathrm{C}$. Standard assays (Arnold \& Garrison, 1979) were done in the presence of $10 \mathrm{mM}$-substrate and $0.2 \mathrm{M}$-sodium acetate buffer $(\mathrm{pH} 5.0)$, terminated by addition of base, and cleared if necessary by centrifugation. The amount of nitrophenolate ion was calculated from the absorbance at $425 \mathrm{~nm}$.

\section{RESULTS}

\section{Mycelia to yeast transformation}

S. schenckii strain \# 29 readily converts to the yeast phase at $35^{\circ} \mathrm{C}$. Yeast phase cells are ovoid through elongated to cigar-shaped. The ovoid type is not easily distinguished from conidia by 

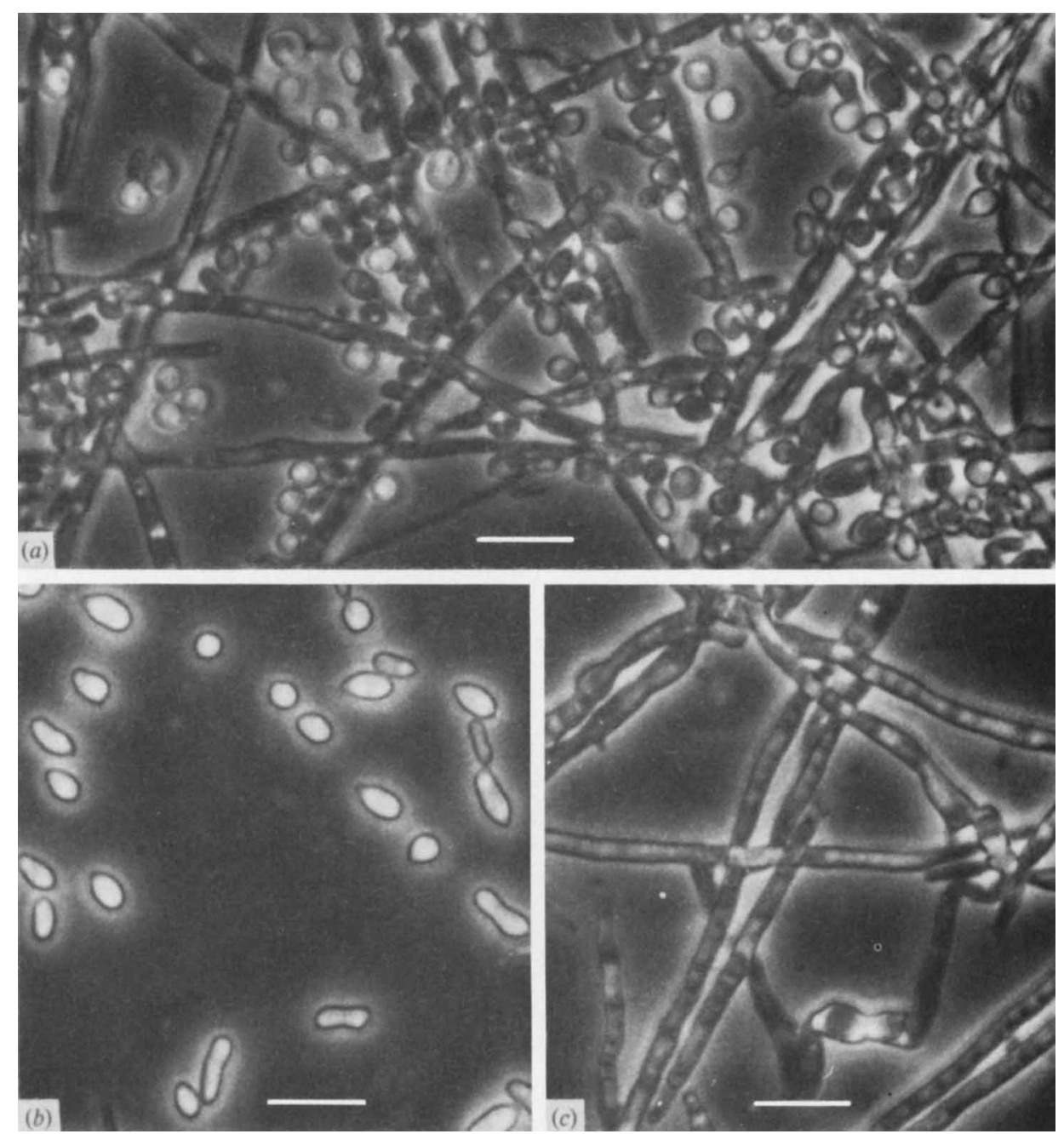

Fig. 1. Light micrographs of $S$. schenckii cells taken from a $3 \mathrm{~d}$ culture on YNG at $20^{\circ} \mathrm{C}$. (a) Mixture of mycelia and conidia before filtration; $(b)$ conidia and $(c)$ mycelia show homogeneous preparations that result from the filtration method. Scale bars, $10 \mu \mathrm{m}$.

light microscopy; however, unambiguous identification can be made by transmission electron microscopy because yeast cells invariably have a microfibrillar zone whereas conidial surfaces are smooth (Garrison et al., 1975).

Conidia and mycelia were separated by filtration under aseptic conditions. From a typical culture at room temperature (Fig. $1 a$ ) reasonably homogeneous preparations of conidia (Fig. $1 b$ ) and mycelia (Fig. 1c) were obtained. To follow transformation of this strain under the conditions used, fresh cultures were initiated from both types of inocula at $35^{\circ} \mathrm{C}$; the resultant growth curves are shown in Fig. 2. The yields were similar after $3 \mathrm{~d}$ but there was a pronounced extension of the lag period when mycelia were the inocula. A mixture of mycelia and conidia (the typical and routine inocula used elsewhere) gave a growth profile that was intermediate between the two curves of Fig. 2.

Conidia (Fig. $1 \mathrm{~b}$ ) produced 'intermediate' cells (Fig. $3 a$ ) within $8-12 \mathrm{~h}$ at $35^{\circ} \mathrm{C}$. It was not uncommon to see two 'germ tubes' on a single conidium. Subsequently, yeast-like cells arose by blastic action (Fig. $3 b$ ) and then underwent further budding either while attached (to form 


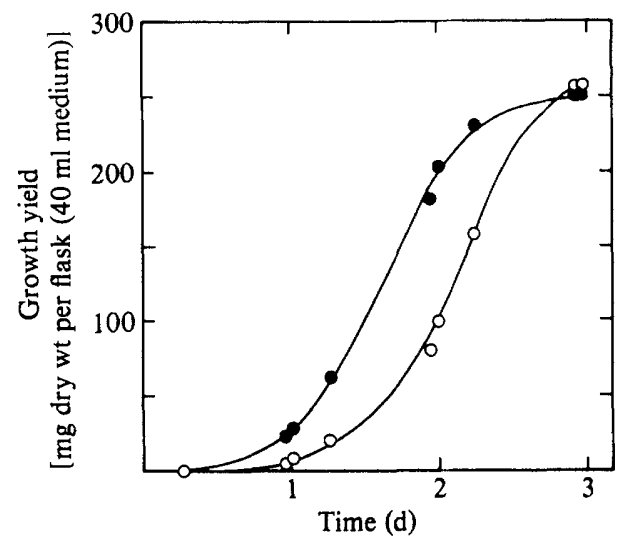

Fig. 2. Growth of $S$. schenckii at $35^{\circ} \mathrm{C}$ using an inoculum of either conidia (O) or mycelia (O).
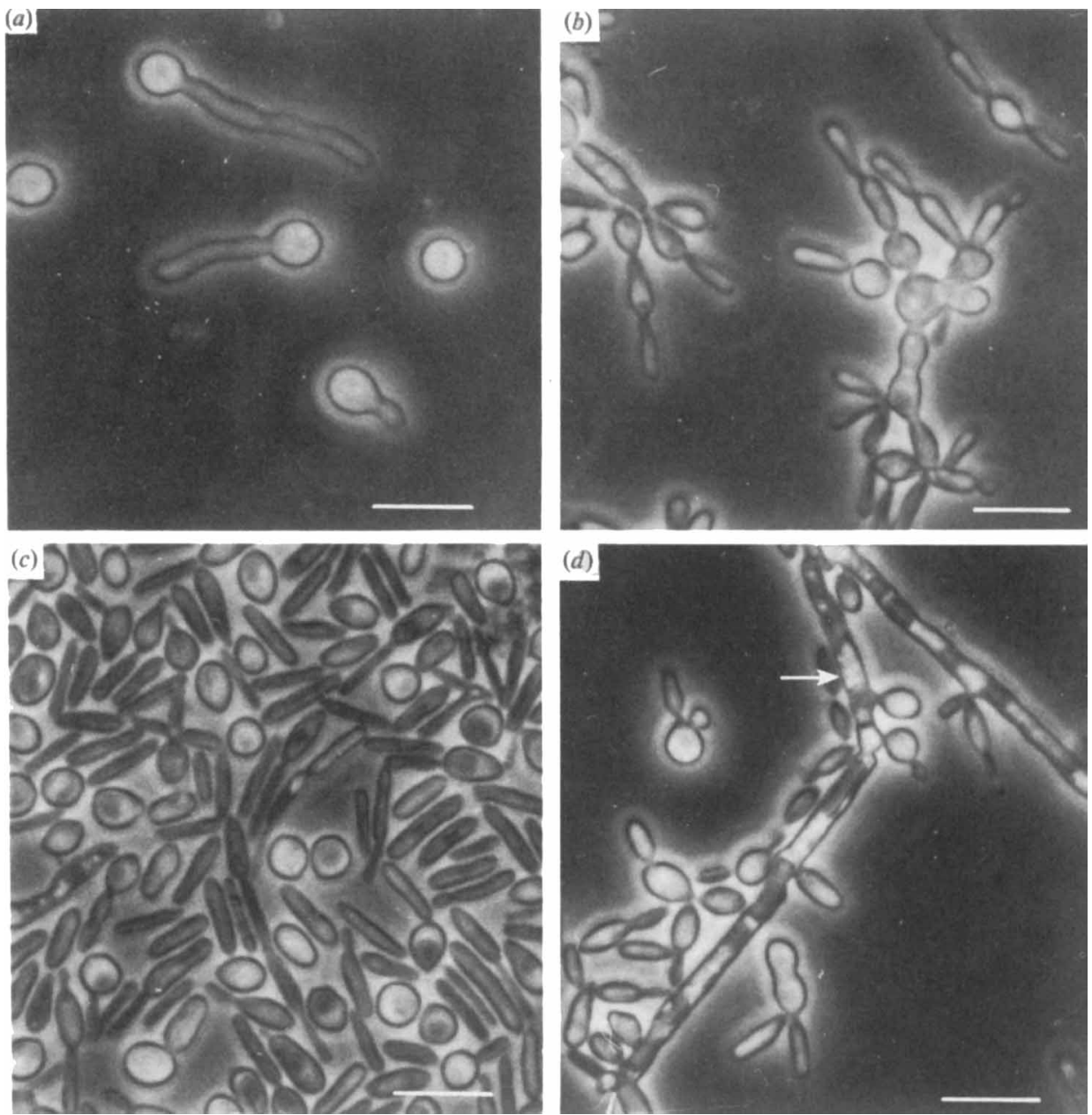

Fig. 3. Transformation into yeast. Conidia were inoculated into new medium at $35^{\circ} \mathrm{C}$ and growth was monitored (Fig. 2). (a) 'Intermediate cells' which arose by germination of conidia $(t=8 \mathrm{~h}) ;(b)$ budding yeast cells $(t=29 \mathrm{~h}) ;(c)$ yeast $(t=72 \mathrm{~h})$. A mycelial inoculum occasionally displayed apparent segmentation (arrow) reminiscent of oidia generation $(d)$. Scale bars, $10 \mu \mathrm{m}$. 
clusters) or after separation so that eventually only yeast cells were seen (Fig. $3 c$ ). It was not surprising that the original cell types were not encountered after $3 \mathrm{~d}$ growth at $35^{\circ} \mathrm{C}$ because cell mass increased by two orders of magnitude. With this strain, under these conditions, macrospores (Mariat et al., 1978) were not seen.

Alternatively, when mycelial elements (Fig. $1 \mathrm{c}$ ) were used as inoculum at $35^{\circ} \mathrm{C}$, there was a considerable lag period (Fig. 2) before significant growth was observed. Our results support the hypothesis of Garrison et al. (1982) that the conidium of $S$. schenckii is the primary infective unit. After $24 \mathrm{~h}$ the culture contained mycelia together with numerous new conidia; events thereafter were as described above for the conidial inoculum. The formation of yeast cells via oidia (Garrison et al., 1975) was not a frequent event although occasional indications of this type of cell arising directly from within mycelia (Fig. $3 d$ ) were noted. Other cell shapes and modes of formation, described for more pleomorphic strains by Mariat et al. (1962) and other investigators, were not encountered here.

Effect of the medium on acid phosphatase activity. Various media were evaluated in terms of growth rate and yield, fidelity of cell type, and specific activity of acid phosphatase of $S$. schenckii. Preliminary trials indicated no advantage with BHI [used previously by Garrison \& Arnold (1983)] in yeast culture. The consistent ability to generate mycelia or yeast on YNG by adjusting the growth temperature recommended this medium for all subsequent studies (at least for this particular strain). For $3 \mathrm{~d}$ cultures on YNG the specific activity of acid phosphatase in intact yeast, conidia and mycelia was 5, 6 and $14 \mathrm{IU}(\mathrm{g} \text { dry wt })^{-1}$, respectively.

The effects of phosphate concentration on the yield of acid phosphatase were determined by using the media described in Methods. Enzyme activities of intact cells, broken cells and cellfree extracts followed the same trends. The synthesis of acid phosphatase by mycelial cells was slightly repressed (about $20 \%$ ) by a high phosphate concentration in the medium; this was relieved in the low phosphate medium (' $\mathrm{S}$ ' medium), i.e. derepression with about $25 \%$ increase over controls on YNG. On the other hand acid phosphatase synthesis in yeast cells was stimulated about $60 \%$ by a high phosphate concentration which contrasts with many observations on Saccharomyces cerevisiae and other yeasts (Arnold, 1981) for which acid phosphatase synthesis is repressed by high phosphate in the medium.

\section{Cell disruption}

In terms of degree of breakage the French pressure cell, X-press, and Bead-Beater were best for yeast, conidia, and mycelia, respectively. However, the highest enzyme activities were usually recorded after cell suspensions were passed 2 or 3 times through the French pressure cell. We estimated that $85-95 \%$ of the cells were broken (as observed by light microscopy) by these treatments although some variation in degree of breakage occurred from one trial to the next. In all cases mechanical disruption exposed a significant fraction of acid phosphatase in contrast with Sacch. cerevisiae (Arnold, 1981) in which the bulk of the acid phosphatase is in the cell envelope. The results of 11 separate trials, all with the French pressure cell, are summarized in Table 1.

\section{Fractionation of broken yeast cells}

The large fraction of acid phosphatase associated with membranes and cellular debris is of interest, particularly for the yeast cells, and we attempted to solubilize it. Table 2 summarizes results on one batch of yeast that was broken in the French pressure cell and then serially extracted with buffer, $0 \cdot 1 \%(\mathrm{v} / \mathrm{v})$ Triton X-100 (detergent) and $50 \%(\mathrm{v} / \mathrm{v}$ ) ethylene glycol (to disrupt hydrophobic bonds). The enzyme activity accounted for in broken cell fractions was $86 \%$ which is adequate considering the number of steps; it also indicates that the enzyme is reasonably stable. The readily solubilized fraction in this trial was $42 \%$ of the activity in the broken cell suspension. Of the $58 \%$ remaining attached to cell remnants, $11 \%$ was dislodged by detergent and a further $5 \%$ by ethylene glycol. 
Table 1. Effect of cell disruption on acid phosphatase activity

\begin{tabular}{|c|c|c|c|}
\hline \multirow[b]{2}{*}{ Cell type } & \multirow[b]{2}{*}{$\begin{array}{c}\text { Growth } \\
\text { temperature } \\
\left({ }^{\circ} \mathrm{C}\right)\end{array}$} & \multicolumn{2}{|c|}{ Acid phosphatase activity* } \\
\hline & & $\begin{array}{l}\text { Percentage increase } \\
\text { after breaking } \\
\text { (mean } \pm \text { SD) }\end{array}$ & $\begin{array}{c}\text { Percentage } \\
\text { soluble } \dagger\end{array}$ \\
\hline Mycelia + conidia & 20 & $146 \pm 25(6)$ & $60 \pm 6$ \\
\hline Mycelia only & 20 & 169 & 69 \\
\hline Conidia only & 20 & 110 & 56 \\
\hline Yeast & 35 & $54 \pm 13(3)$ & $32 \pm 12$ \\
\hline
\end{tabular}

Table 2. Fractionation of broken yeast cells

Preparation or derivative fraction

Cell suspension

Broken cell suspension

Cell-free extract

Buffer wash of sediment

Triton X-100 wash

Ethylene glycol wash

Final buffer wash

Resuspended extracted debris
Acid phosphatase

(IU)*

$10 \cdot 7$

$17 \cdot 8$

$6 \cdot 85$

0.65

$0 \cdot 84$

$0 \cdot 41$

$0 \cdot 12$

$6 \cdot 45$

* The total number of units in each preparation was adjusted to the initial sample, viz. $35 \mathrm{ml}$ of $20 \%$ suspension.

\section{Electrophoretic analyses}

Preliminary trials indicated that the optimum solution for extraction of acid phosphatases

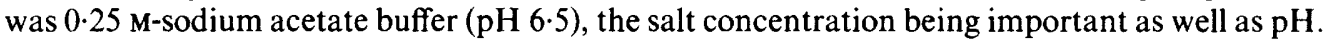
The enzymes were reasonably stable between $\mathrm{pH} 2.5$ and 7.5 but inactivation was significant at higher or lower $\mathrm{pH}$ values. Since the stability of crude extracts was lowered by reducing the salt concentration (e.g. by overnight dialysis in the cold against dilute buffers) the gel permeation method was used for sample manipulation before electrophoresis. In this manner the proteins were gently transferred to low conductivity medium; the choices of $\mathrm{pH} 7.5$ for samples and 8.0 for electrophoresis were compromises consistent with retention of enzyme activity and reasonable anionic mobility. Controlled experiments indicated that cleaning the gels by pre-electrophoresis was advantageous in terms of retaining enzyme activity during separations and in achieving a stable and consistent current flow.

\section{Isoenzyme patterns}

The acid phosphatase isoenzyme patterns for mycelia (cultured at $20^{\circ} \mathrm{C}$ ), conidia $\left(20^{\circ} \mathrm{C}\right)$ and yeast cells $\left(35^{\circ} \mathrm{C}\right)$ are shown in the examples, which were taken from the same electrophoretic run, in Fig. 4. It is clear that some acid phosphatase activity remained at the origin; the relative amount was much greater for the yeast extract than for the mycelial extract (Fig. $4 b$ ). The redbrown dye product is more difficult to photograph (in black and white) than other stains, so that lower activities (e.g. Y-IV and Y-V) were difficult to reproduce. Yeast isoenzyme II seemed to exhibit microheterogeneity and the components were labelled Y-II $a$ to Y-Ile. An enlarged reproduction that demonstrates the $\mathrm{Y}$-II isoenzymes is shown in Fig. $5 b$. Isoenzymes M-II and C-II are different from Y-II and Y-III (Fig. 4a). There was an indication from mixing experiments (Fig. 5c) that the fairly disperse bands of M-II and C-II had slightly different mobilities that overlapped in admixture.

Some extractions were made in the presence of cysteine, dithiothreitol, chelating agents and detergents that were selected for ameliorating effects on possible artifacts of oxidation, 


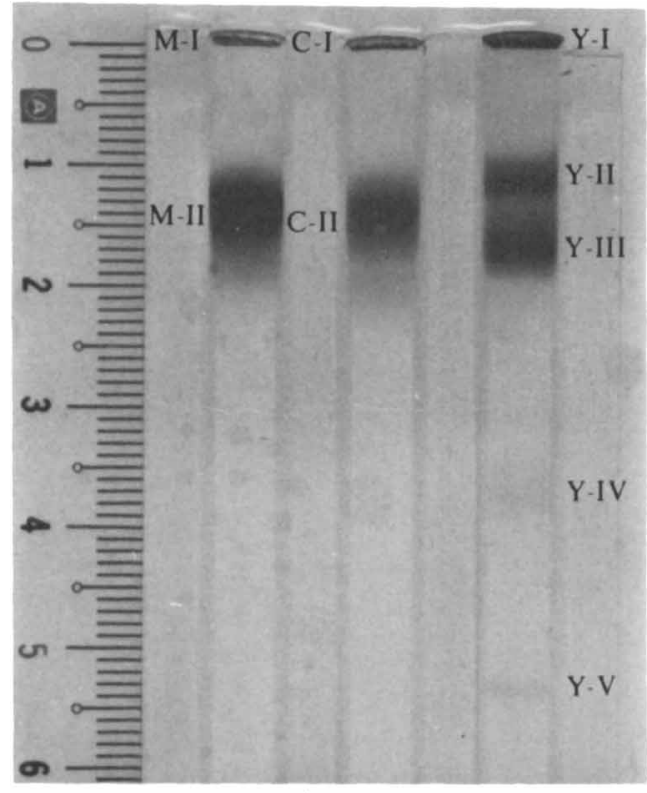

(a)

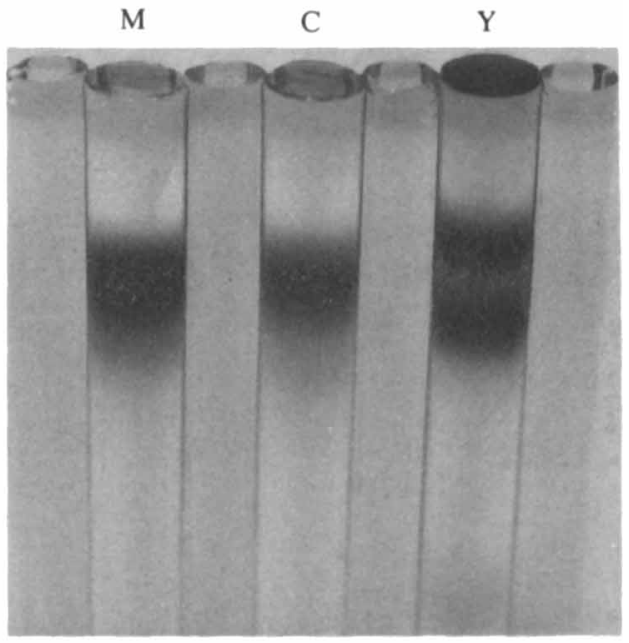

(b)

Fig. 4. Enzymograms. Extracts of mycelia (M), conidia (C) and yeast (Y) were subjected to electrophoresis and then stained for acid phosphatase activity. The small scale divisions are in $\mathrm{mm}$. The origin is at the top. (a) Gels from the same run showing isoenzyme labels; $(b)$ the same gels photographed at an angle so that relative intensities of $\mathrm{M}-\mathrm{I}<\mathrm{C}-\mathrm{I} \ll \mathrm{Y}-\mathrm{I}$ are apparent.

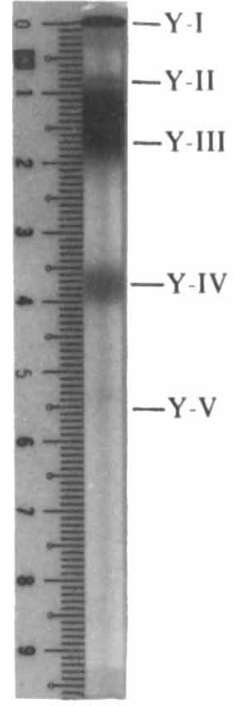

(a)

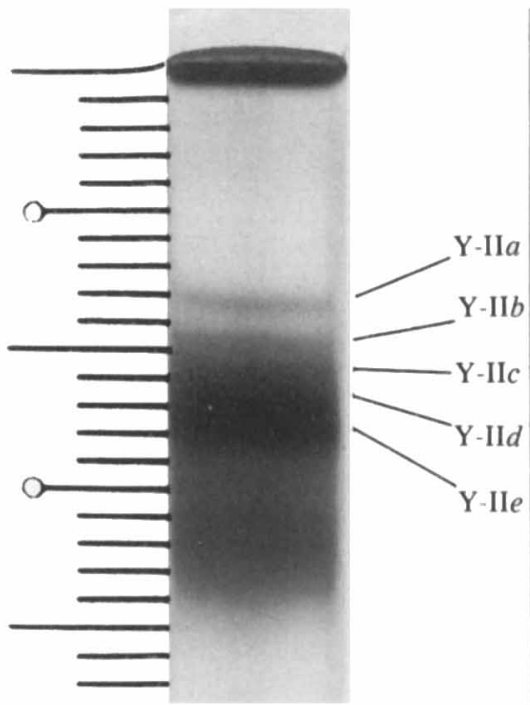

(b)
M

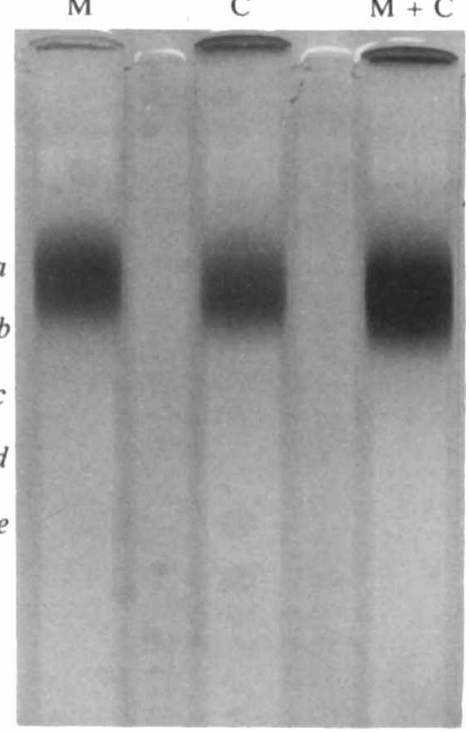

(c)

Fig. 5. (a) Acid phosphatases of yeast; (b) close-up of the same gel showing isoenzymes within the Y-II set; $(c)$ enzymograms for mycelia $(M)$ and conidia $(C)$ and for a mixture of the same extracts $(M+C)$. 


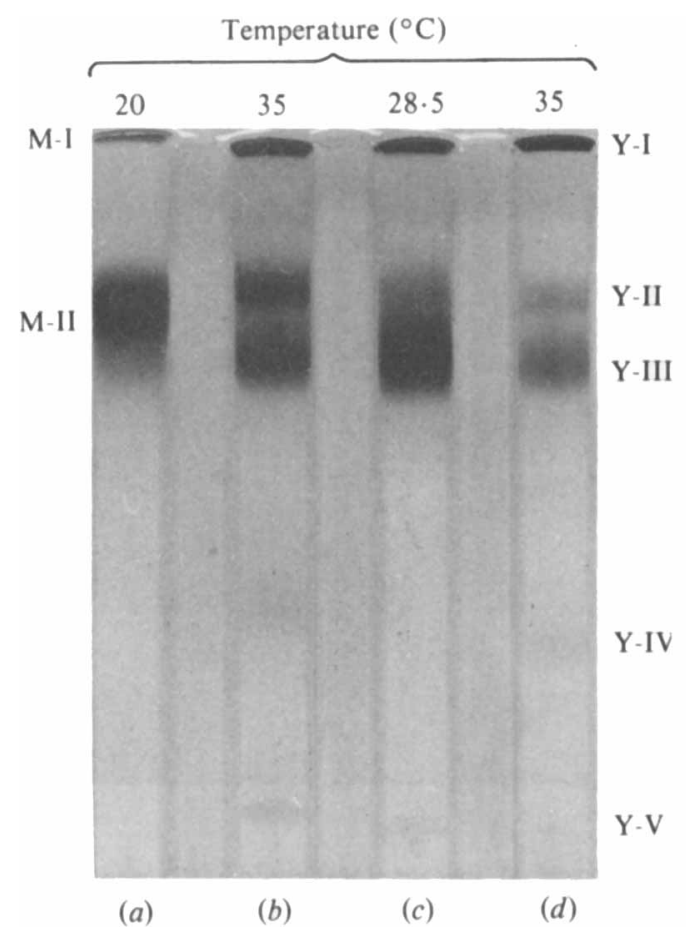

Fig. 6. Transition cells. Extracts were obtained from mycelia grown at $20^{\circ} \mathrm{C}(a)$, yeast grown at $35^{\circ} \mathrm{C}$ (b), cells, mostly yeast, grown at $28.5^{\circ} \mathrm{C}(c)$ and cells of the 'intermediate' type after $16 \mathrm{~h}$ culture of a conidial inoculum at $35^{\circ} \mathrm{C}$ as in Fig. $3 a(d)$.

denaturation or aggregation of the acid phosphatase isoenzymes. None of these altered the electrophoretic patterns significantly. The substantial amount of Y-I is notable in this context but pretreatments explored to date did not deplete this band in favour of a component that penetrated standard gels.

\section{Isoenzymes of transition}

A limited number of cultures were grown at temperatures between $20^{\circ} \mathrm{C}$ (for mycelia and conidia) and $35^{\circ} \mathrm{C}$ (for yeast); they yielded a mixture of cell types. At $28.5^{\circ} \mathrm{C}$ the cell type was predominantly yeast-like, and cell-free extracts had strong activities of $Y$-I and Y-III, a low (but typical) activity of Y-V, no Y-IV and relatively low activity of Y-II (Fig. 6). In another experiment conidia were purified and used to initiate a culture at $35^{\circ} \mathrm{C}$ (see Fig. 2). At $16 \mathrm{~h}$ transition cells of the type shown in Fig. $3 a$ were prevalent and a sample was taken for electrophoretic analysis. This indicated that isoenzymes Y-I and Y-III, some components of Y-II, and traces of Y-IV and Y-V, had already appeared (Fig. $6 d$ ).

\section{Phosphate nutrition and isoenzyme pattern}

Two separate experiments compared the isoenzyme patterns within extracts from yeast cells cultured on normal medium ( $2 \mathrm{mM}$-phosphate), high phosphate (18 mM) and low phosphate ('S' medium); the results are summarized by the examples in Fig. 7. High phosphate restricted the synthesis of Y-II $a$ and Y-II $b$, and increased the relative amount of Y-III. Low phosphate restricted the synthesis of Y-IV and stimulated the synthesis of all Y-II isoenzymes relative to Y-III.

\section{Acid phosphatase inhibitors}

Inhibition studies were done under controlled conditions by inclusion of various potential inhibitors in the detection reagent mixture (see Methods). The effects of three inhibitors are 


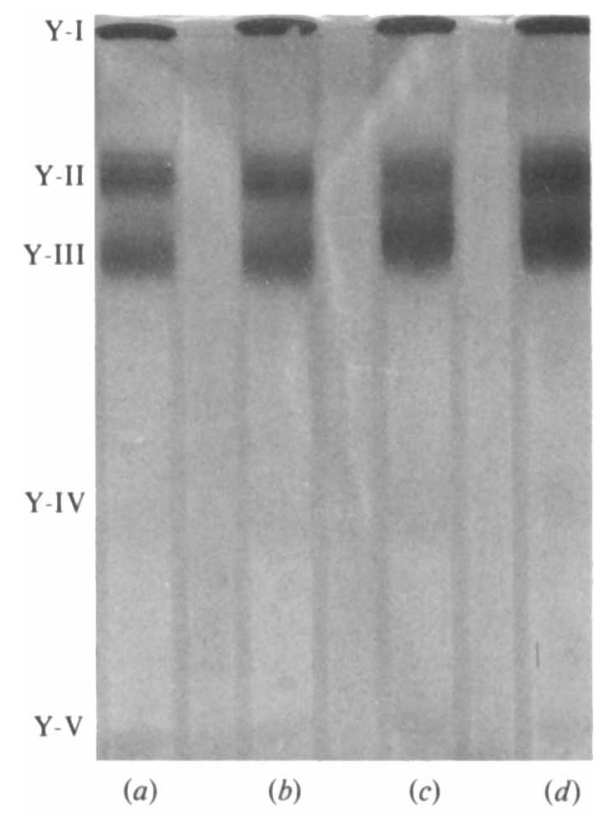

Fig. 7. Effect of phosphate nutrition. Extracts of yeast cells grown at $35^{\circ} \mathrm{C}$ on YNG (a), YNG + $16 \mathrm{mM}$-phosphate $(b)$ and, in a separate experiment, YNG $(c)$ and ' $\mathrm{S}$ ' medium, i.e. low phosphate $(d)$.

Table 3. Effects of inhibitors on acid phosphatase

Extracts of cells were electrophoresed at $\mathrm{pH} 8.0$ and then stained for acid phosphatase activity at $\mathrm{pH} 5 \cdot 0$ in the presence of various inhibitors. Inhibitors were classified as strong ( $75-100 \%$ inhibition), moderate $(25-74 \%$ inhibition), or weak (trace- $24 \%$ inhibition).

\begin{tabular}{|c|c|c|c|}
\hline \multirow[b]{2}{*}{ Isoenzyme } & \multicolumn{3}{|c|}{ Extent of inhibition by: } \\
\hline & $\begin{array}{l}\mathrm{L}(+) \text {-tartrate } \\
\quad(40 \mathrm{mM})\end{array}$ & $\begin{array}{l}\text { phosphate } \\
\text { (40 mM) }\end{array}$ & $\begin{array}{c}\text { fluoride } \\
(1 \mathrm{mM})\end{array}$ \\
\hline Y-I & None & Moderate & Strong \\
\hline Y-II $a$ & Strong & None & Strong \\
\hline$b$ & Moderate & None & Strong \\
\hline$c$ & Weak & None & Strong \\
\hline$d$ & None & None & Moderate \\
\hline$e$ & None & None & Moderate \\
\hline Y-III & Strong & Weak & Strong \\
\hline Y-IV & Strong & Strong & Strong \\
\hline $\mathrm{Y} \cdot \mathrm{V}$ & None & None & None \\
\hline M-I & None & Moderate & Strong \\
\hline M-II & Strong & Moderate & Strong \\
\hline
\end{tabular}

summarized in Table 3. A limited number of studies with conidial extracts indicated that the inhibition pattern was very similar to that obtained with mycelial extract.

Garrison \& Arnold (1983), in their cytochemical studies on $S$. schenckii acid phosphatases, found that $10 \mathrm{~mm}$-sodium fluoride obliterated the multiplicity of positive sites normally revealed by the Gomori reaction in fixed specimens of yeast and mycelia. Subsequent work in this laboratory indicated concentrations as low as $0.1 \mathrm{~mm}$ were effective. Fluoride acted both as a reversible and an irreversible inhibitor depending upon the particular isoenzyme. Substrates, phosphate and citrate all protected the enzyme from fluoride inactivation. The kinetics and mechanism of fluoride inactivation have been examined in some detail and a fuller account will be published separately. 


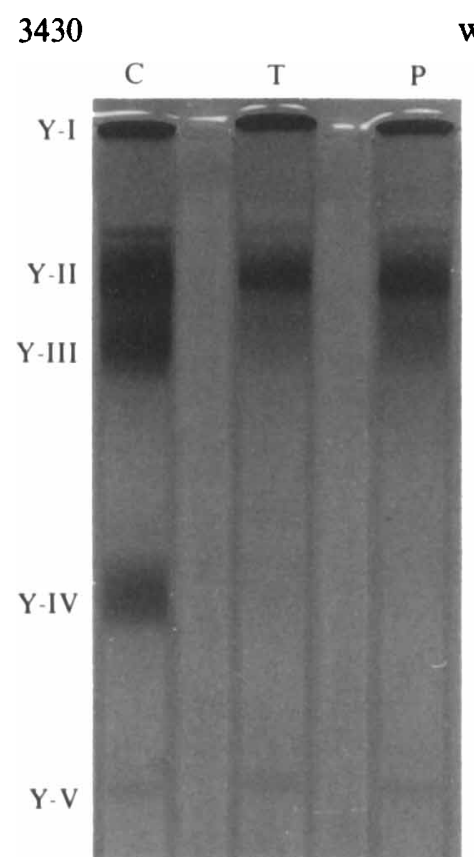

(a)

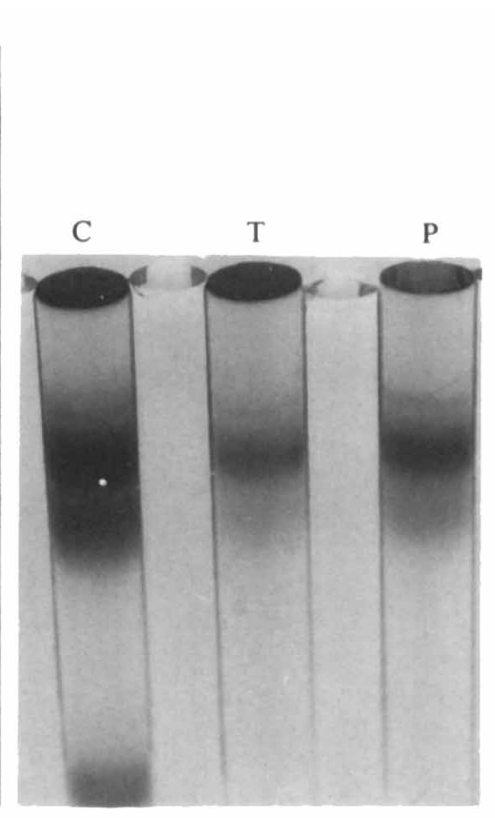

(b)

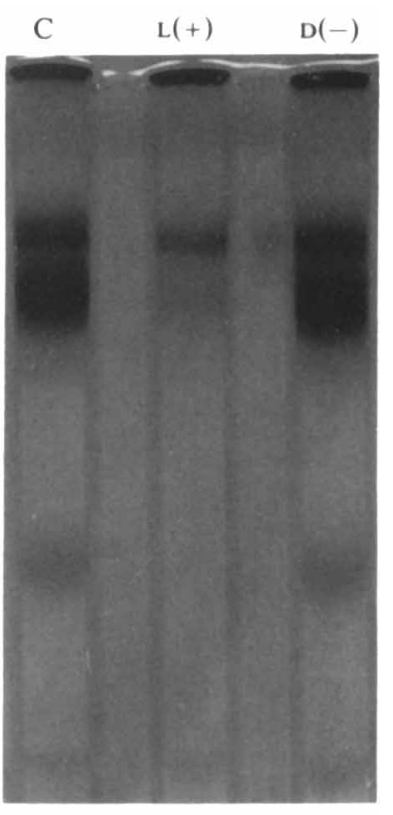

(c)

Fig. 8. Inhibition patterns. (a) Yeast extracts were electrophoresed and then stained with normal reagent $(C)$ or with the addition of $40 \mathrm{mM}-\mathrm{L}(+)$-tartrate $(T)$, or with $40 \mathrm{~mm}$-phosphate $(P) ;(b)$ the same gels photographed at an angle so that relative activities of Y-I are apparent; $(c)$ stereospecificity of tartrate inhibition. (Detection reagent contained no addition (C) or $40 \mathrm{mM}-\mathrm{L}(+)$ - or $\mathrm{D}(-)$-tartaric acid. Only the $\mathrm{L}(+)$-isomer caused inhibition.)

The effects of $\mathrm{L}(+)$-tartrate and phosphate on acid phosphatase isoenzymes in yeast extracts are shown in Fig. 8. Isoenzyme Y-I was inhibited by phosphate but not tartrate (Fig. $8 b$ ). The most sensitive isoenzymes were Y-III and Y-IV (Fig. 8a). The specificity of $\mathrm{L}(+)$-tartrate is indicated by the gels in Fig. $8 c$ which show that an equal concentration of $\mathrm{D}(-)$-tartrate had no effect.

\section{Other factors affecting the isoenzyme pattern}

The mycelial and conidial isoenzymes detected in gels were slightly stimulated by replacing acetate buffer with citrate buffer in the activity stain; the same was true for the Y-II group but Y-III and Y-IV were less active with citrate as the buffer. Isoenzymes Y-II $a$ to Y-II $e$ were most sensitive to ageing of the extract; Y-II $a$ and $\mathrm{Y}$-II $b$ disappeared after a few days at $4{ }^{\circ} \mathrm{C}$. On the basis of just two separate experiments to date there is some indication that the zones of the Y-II isoenzymes were sharpened by preincubation with neuraminidase.

\section{DISCUSSION}

$S$. schenckii is a useful model for studying the phenomenon of dimorphism because it can be manipulated between the mycelial and yeast phases with ease. The present work demonstrates that for strain \# 29 at least the mycelial (plus conidia) or yeast phase can be produced on the same medium simply by regulating the temperature. Thus the further complications of more complex media and the interpretation of their possible effects are avoided. YNG was chosen in lieu of a completely synthetic medium after consideration of cost, higher buffering capacity (due to the neopeptone component), and prior usefulness for a variety of yeast and yeast-like organisms in this and other laboratories. Standard temperatures of 20 and $35^{\circ} \mathrm{C}$ were chosen to maximize the fidelity of cell type, although the general findings reported here were also observed 
with mycelia grown at any temperature between 18 and $25^{\circ} \mathrm{C}$ and in contradistinction to yeast grown over the range $30-37^{\circ} \mathrm{C}$. Although temperature has a profound effect on morphology and we found a concomitant effect on acid phosphatase isoenzyme pattern it is not possible at present to study the corollary, namely to ask what effect temperature has on cells of constant morphology.

It should be noted that $S$. schenckii can be maintained in the yeast phase (on YNG at $35^{\circ} \mathrm{C}$ ) for two or three successive batch cultures, after which the vitality of the organism is notably compromised; this phenomenon has also been observed for other strains and with other more complex media and may be general. For this reason we maintain the organism in the mycelial phase. It is the working hypothesis of this laboratory that the yeast phase of $S$. schenckii is a manifestation of the organism's ability to 'survive' an unfavourable higher temperature.

We have documented differences in the acid phosphatase isoenzyme patterns of mycelia, conidia and yeast. $S$. schenckii has the capacity to synthesize a multiplicity of electrophoretically distinct acid phosphatases, the expression of various isoenzymes being controlled by growth temperature. The differences in sensitivity to inhibitors demonstrated here will be useful in confirming the identity of individual isoenzymes after their purification from crude extracts. The functions of the various isoenzymes are not yet known, and it should be stressed that present assays were based on just two substrates, $p$-nitrophenyl phosphate and $\alpha$-naphthyl phosphate. Preliminary studies have indicated that some of the isoenzymes are capable of catalysing the release of phosphate from phosphoproteins such as casein and phosvitin so that it will be of interest to determine whether they function in the dephosphorylation of other enzymes or membrane components within the native cells.

Garrison \& Arnold (1983) established a multiplicity of activity sites for acid phosphatase within both yeast and mycelial cells of $S$. schenckii. The present work adds to that knowledge by demonstrating both extracytoplasmic and cytoplasmic components that can be assayed in intact versus broken cells. The microfibrillar zone that adorns the yeast cell is particularly rich in acid phosphatase activity and may be a part of the large fraction that is easily sedimented from broken cell preparations. Matching the various isoenzymes with their subcellular activity sites would be of obvious value and we are utilizing inhibitors as one approach. Although several avenues can be explored (Arnold, 1981) it is unfortunate that three effectors, viz. tartaric, phosphoric and citric acids, are all incompatible with the Gomori (1950) procedure of cytochemistry.

Our observations on the acid phosphatase isoenzyme patterns for the different cell types of $S$. schenckii find no precedent in studies with any other dimorphic fungus to our knowledge. Our findings raise several questions about the function of the various isoenzymes, their substrate specificities, possible control mechanisms involving other enzymes, and whether they have a direct role in morphogenesis. All of these items may be addressed after the isoenzymes have been purified or at least separated from each other. The increased number of isoenzymes in the pathogenic phase of $S$. schenckii raises the question of whether they play any direct role in the pathogenic process; their inclusion on the microfibrillar zone (Garrison \& Arnold, 1983) would certainly allow for interaction with macrophages and other host cells. Remaley et al. (1984) have suggested a direct interaction of an acid phosphatase on the surface of the protozoan Leishmania donovani with macrophages.

We thank Brenda Evans for technical assistance with the early aspects of this investigation and Dr Archie Murdock for helpful discussions. The work was supported by US Public Health Service Grant AI20761 to W.N.A.

\section{REFERENCES}

ARNOLD, W. N. (1981). Enzymes. In Yeast Cell Envelopes: Biochemistry, Biophysics and Ultrastructure, vol. 2, pp. 1-46. Edited by W. N. Arnold. Boca Raton, Florida: CRC Press.
ARNold, W. N. \& Garrison, R. G. (1979). An Fe $\mathrm{Fe}^{3+}$ activated acid phosphatase in Saccharomyces rouxii. Journal of Biological Chemistry 254, 4919-4924.

Bestic, P. B. \& ARNOLD, W. N. (1976). Linear 
transformation of standard curves for yeast turbidity. Applied and Environmental Microbiology 32, 640-641.

Darling, S., Theilande, J. \& Birch-Andersen, A. (1969). Kinetics and morphological observations on Saccharomyces cerevisiae during spheroplast formation. Journal of Bacteriology 98, 797-810.

Davis, B. J. \& ORNSTEIN, L. (1959). High resolution enzyme localization with a new diazo reagent, hexazonium pararosaniline. Journal of Histochemistry and Cytochemistry 7, 297-298.

Garrison, R. G. \& ARnold, W. N. (1983). Cytochemical localization of acid phosphatases in the dimorphic fungus Sporothrix schenckii. Current Microbiology 9, 253-258.

Garrison, R. G., Boyd, K. S. \& Mariat, F. (1975). Ultrastructural studies of the mycelium to yeast transformation of Sporothrix schenckii. Journal of Bacteriology 124, 959-968.

Garrison, R. G., Mariat, F., Fromentin, H. \& MiRIKITANI, F. (1982). Electron microscopic analysis of yeastlike cell formation from the conidia of Sporothrix schenckii. Annales de l'Institut Pasteur/ Microbiologie 133B, 189-204.

GOMORI, G. (1950). An improved histochemical technique for acid phosphatase. Stain Technology 25, 8185.
Huerten, S., Jerstedt, S. \& Tiselius, A. (1965). Some aspects of the use of continuous and discontinuous systems in polyacrylamide gel electrophoresis. Analytical Biochemistry 11, 219-223.

Mariat, F., Garrison, R. G., Boyd, K. S., Rouffaud, M. A. \& Fromentin, H. (1978). Premières observations sur les macrospores pigmentes de Sporothrix schenckii. Comptes rendu hebdomadaires des séances de l'Académie des sciences 286, 1429-1432.

Mariat, F., Lavalle, P. \& Destombes, P. (1962). Recherches sur la Sporotrichose. Sabouraudia 2, 6079.

Remaley, A. T., Kuhns, D. B., Basford, R. E., Glew, R. H. \& KAPLAN, S. S. (1984). Leishmanial phosphatase blocks neutrophil $\mathrm{O}_{2}^{-}$production. Journal of Biological Chemistry 259, 11173-11175.

RoBinOw, C. F. (1975). The preparation of yeasts for light microscopy. Methods in Cell Biology 11, 1-22.

Travassos, L. R. \& Lloyd, K. O. (1980). Sporothrix schenckii and related species of Ceratocystis. Microbiological Reviews 44, 683-721.

Walbaum, S., Duriez, T., Dujardin, L. \& Biguet, J. (1978). Étude d'un extrait de Sporothrix schenckii (forme levure). Analyse électrophorétique et immunoélectrophorétique; charactèrisation des activités enzymatiques. Mycopathologia 63, 105-111. 